\title{
Critérios de qualidade dos periódicos eletrônicos em acesso aberto da região Ibero-Americana na área de tecnologias educativas, indexados na base de dados Latindex
}

\section{Quality criteria for open access electronic journals of the Ibero-American region in the area of educational technologies indexed in the Latindex database}

\author{
Claudia Maria Pecegueiro ${ }^{1}$, Iraceles Luzo ${ }^{2}$ \\ ${ }^{1}$ Universidade Federal do Maranhão - UFMA, São Luís, MA, Brasil. ORCID: http://orcid.org/0000-0002-8670-330X \\ 2 Universidade Federal do Maranhão - UFMA, São Luís, MA, Brasil. ORCID: : https://orcid.org/0000-0002-5884-7656
}

Autor para correspondência/Mail to: Claudia Maria Pecegueiro, clpecegueiro@gmail.com

Recebido/Submitted: 19 de dezembro de 2019; Aceito/Approved: 05 de julho de 2020

Copyright (C) 2020 Pecegueiro \& Iraceles. Todo o conteúdo da Revista (incluindo-se instruções, política editorial e modelos) está sob uma licença Creative Commons Atribuição-NãoComercial-Compartilhalgual 3.0 Não Adaptada. Ao serem publicados por esta Revista, os artigos são de livre uso em ambientes educacionais, de pesquisa e não comerciais, com atribuição de autoria obrigatória. Mais informações em http://revistas.ufpr.br/atoz/about/submissions\#tcopyrightNotice.

\begin{abstract}
Resumo
Introdução: Estuda os aspectos teóricos relacionados ao periódico científico, instrumento de divulgação dos resultados de pesquisas concluídas ou em andamento, no que se refere aos critérios internacionais de avaliação que imprimem qualidade à publicação. Objetivo: A pesquisa responde ao questionamento: de que forma os periódicos dos países ibero-americanos sobre tecnologias educativas obedecem aos critérios de qualidade estabelecidos no catálogo 2.0 pela Latindex? Objetiva analisar, a partir dos critérios estabelecidos no catálogo 2.0 da Latindex, os periódicos na área de ciências sociais, com o subtema tecnologias educativas e de acesso livre. Metodologia: Utiliza como campo de pesquisa o Sistema Regional de Información en Línea para Revistas Científicas de América Latina, el Caribe, España y Portugal - Latindex. O Latindex têm dentre seus objetivos proporcionar aos periódicos ibero-americanos maior visibilidade e cobertura internacional em termos de informação, documentação e publicação científica. A coleta de dados foi realizada diretamente na base Latindex por meio da busca avançada, que permite a consulta da área, do país e do suporte (impresso ou eletrônico) em que o periódico se encontra. Conclusão: Conclui que a maioria dos periódicos não preenche os 38 critérios estabelecidos pela base, que o periódico peruano Hamut'ay foi o único a pontuar em todos os critérios estabelecidos e os periódicos que menos pontuaram foram o espanhol AP: Online Journal in Public Archeology, e o mexicano Travaux et Recherches Dans les Amériques du Centre - Trace.
\end{abstract}

Palavras-chave: Avaliação de Periódico; Periódico científico; Latindex.

\begin{abstract}
Introduction: It studies the theoretical aspects related to the scientific journal, an instrument for disseminating the results of completed or ongoing research, concerning international evaluation criteria that gives quality to the publication. Objective: The research answeres the research question how do Ibero-American journals that address educational technologies meet the quality criteria set out in Latindex catalog 2.0? It aims to analyze, based on the criteria established in Latindex catalog 2.0, the journals in the social sciences area, with the sub-theme educational and open access technologies. Method: It uses as its field of research the Sistema Regional de Información en Línea para Revistas Científicas de América Latina, el Caribe, España y Portugal - Latindex. Latindex objectives are to give Ibero-American journals greater visibility and international coverage in terms of information, documentation, and scientific publication. Data collection was performed directly in the Latindex database, through the advanced search that allows the consultation of the area, country and support (printed or electronic) in which the journal is located. Conclusion: It concludes that most journals do not fill the 38 criteria established by the database, that the Peruvian Hamut'ay was the only one to score in all the established criteria and the journals, which scored lower, were Spanish AP: Online Journal in Public Archeology, and the Mexican Travaux et Recherches Dans les Amériques du Center - Trace.
\end{abstract}

Keywords: Journal evaluation; Scientific journal; Latindex

\section{INTRODUÇÃO}

A comunicação científica refere-se à informação apresentada em congressos, simpósios, reuniões e demais encontros da área acadêmica, seguida de publicação em anais e periódicos científicos. Meadows (1999) afirma que não há como precisar a primeira comunicação científica, mas, pela tradição, a pesquisa comunicada de forma escrita é atribuída a Aristóteles.

O advento da imprensa no século XV na Europa foi um marco para a comunicação científica e para a divulgação progressiva do conhecimento científico produzido na época. Ela acelerava o processo de publicação e a distribuição tornou-se mais "farta". Nesse contexto, o livro passou a ser o principal canal de divulgação e disseminação das pesquisas, como afirma Corrêa e Miranda (2016, p. 53): "Antes da invenção da imprensa, no continente Europeu, o conhecimento circulante era restrito a pequenos grupos detentores do poder e riqueza". Em outra perspectiva, Fukahori (2017, p. 23-24) fala que: "Além do livro, antes da divulgação final dos resultados de pesquisas, era comum a comunicação por cartas entre os amigos pesquisadores. O andamento das investigações era compartilhado [...] favorecendo as discussões". Contudo, a troca de correspondência, por ser de caráter 
pessoal, era limitada e não oportunizava grandes discussões; e os livros, além de trazerem conhecimentos já sedimentados, tinham ainda o entrave da demora da publicação.

Com os tipos móveis, o novo modelo de publicação científica, periódico científico, passou a ser outro meio utilizado para divulgação dos resultados de pesquisas, assim como para a comunicação entre pares, servindo então como fonte de referência a estudos em andamento.

Hodiernamente, a atividade científica se encontra estruturada em núcleos ou grupos de pesquisas que influenciam fundamentalmente na investigação de cada membro do grupo. Quanto ao compartilhamento dessa investigação, a mesma ainda ocorre, porém, de maneira diferente na comunidade científica:

\begin{abstract}
[...] seus membros são os encarregados de reconhecer as necessidades investigativas e executá-las. Os membros de uma comunidade científica estabelecem sua comunicação mediante a disseminação de trabalhos de investigação. A socialização da ciência é elemento essencial e predominante da atividade investigadora (Paz-Enrique, 2018, p. 14, tradução nossa).
\end{abstract}

Cabe esclarecer que somente a publicação do artigo não garante sua legitimação, pois para que isso se dê é necessário que o material publicado seja julgado e aprovado no meio acadêmico e científico por outros pesquisadores (Mueller, 2012).

Os primeiros periódicos científicos de que se tem notícia datam do ano de 1665: Jounal des Sçavants, que tinha como objetivo registrar as informações sobre os livros publicados na Europa, citar as primeiras decisões da corte, divulgar experimentos, descrever invenções e registrar dados meteorológicos; e o Philosophical Transactions of the Royal Society, que objetivava registrar experiências científicas e correspondências trocadas pelos membros da academia.

O Journal des Sçavants e o Philosophical Transactions contribuíram como modelos distintos para a literatura científica: o primeiro influenciou o desenvolvimento das revistas dedicadas à ciência geral, sem comprometimento com uma área específica, e o segundo se tornou modelo das publicações das sociedades científicas, que apareceram em grande número na Europa, durante o século XVIII (Stumpf, 1996, p. 2).

Stumpf (1996) afirma que o periódico científico surgiu devido à necessidade de aprimorar e estender o alcance que essas pesquisas deveriam ter, uma vez que antes as pesquisas se limitavam ao espaço geográfico de onde eram feitas. Pesquisas têm demostrado que os periódicos científicos se mantêm como o principal canal de difusão do conhecimento científico produzido "[...] no entanto, por motivos diversos, o artigo científico vem aumentando de importância em todas as áreas do conhecimento" (Mueller, 2012, p. 133).

Até o fim do século XX, o periódico científico impresso era o único formato disponível na época, porém, a partir do começo dos anos 90 e início do século XXI, com o desenvolvimento rápido da internet, surgem os periódicos científicos eletrônicos, que, além do acesso amplo e fácil aos estudos e pesquisas publicadas e da agilidade na busca e divulgação dos resultados, promovem maior interação e novos padrões de relacionamento entre os pesquisadores, independentemente da sua localização geográfica.

A atividade de avaliar os periódicos científicos não é recente na comunidade científica. Fatores como as diversas formas de publicação de periódicos científicos, o aumento no número de editoras comerciais e de universidades e o Estado editorando e publicando periódicos contribuíram para que, em meados dos anos 1960, começasse a se pensar em métodos e órgãos responsáveis por verificar e avaliar tais publicações.

Em 1964, um grupo de pesquisadores, patrocinados pela UNESCO, reuniu-se em Porto Rico para estudar os problemas dos periódicos científicos e técnicos latino-americanos. Nessa reunião, foram estabelecidos critérios para classificação dos periódicos, conferindo-lhes qualificações entre deficiente a excelente (Passos, Passos, Caregnato, e Silva, 2018, p. 210).

$\mathrm{Na}$ mesma época, Eugene Garfield, fundador e presidente do Institute for Scientific Information (ISI), realiza as primeiras análises estatísticas em larga escala de citações em periódicos, trabalho esse que é considerado como a origem das avaliações de periódicos científicos (Yu et al. como citado em Passos et al., 2018, p. 209-210).

Como salientam Krzyzanowski e Ferreira (1998, p. 166): “A partir da década de 60, encontram-se na literatura estudos sobre avaliação de revistas científicas e técnicas que demonstram a necessidade de se definirem parâmetros mensuráveis, que possam refletir a qualidade da informação registrada". Essa preocupação advém principalmente do aumento expressivo de publicações e crescimento das revistas científicas, como abordam Krzyzanowski e Ferreira (1998, p. 165):

A proliferação de títulos de periódicos nas diversas áreas do conhecimento tem sido preocupação dos profissionais que se interessam pela qualidade da informação científica, sejam autores, editores, publicadores, serviços de indexação, centros de documentação, bibliotecas e, especialmente, pesquisadores (usuários da informação). 
Portanto, mediante a necessidade de avaliar e estabelecer um padrão de qualidade aos periódicos científicos, independentemente do seu formato (impresso e/ou eletrônico), é que são estabelecidos critérios de qualidade. Os critérios de avaliação levam em consideração, na sua maioria, indicadores de conteúdo e de forma, também denominados como aspectos intrínsecos e extrínsecos; além de aspectos científicos e materiais.

Em 1995, de acordo com Barbalho (2005), Castro (2003) e S. Ferreira (2005) adaptam o modelo criado anteriormente por Braga e Obherhofer, em 1982, para avaliar os periódicos latino-americanos indexados na Literatura Latino-Americana e do Caribe em Ciências da Saúde (LILACS) e no MEDlars online (MEDLINE), sendo esta última uma base de dados mantida pela Biblioteca Nacional de Medicina dos Estados Unidos da América.

Os critérios de avaliação presentes no modelo desenvolvido por Braga e Obherhofer em 1982 incluíam as seguintes características: quanto à normalização, tempo de existência da revista, periodicidade, indexação, difusão, colaboração em termos de autoria e autoridade da comissão editorial, revisão por pares, entre outros.

Esses critérios variam de acordo com o órgão que avalia, pois cada um elege seus próprios critérios de avaliação. Como afirma Barbalho (2005, p. 147): "Cada base de dados estabelece os seus princípios para a inserção dos títulos, com base nos objetivos a que se propõe, no público-alvo a que pretende atingir e nas áreas de interesse que contempla".

Outro método de classificação e avaliação de periódicos científicos que se pode citar é a Classificação Integrada de Revistas Científicas (CIRC). A CIRC (https://clasificacioncirc.es/clasificacion-circ, recuperado em 2019), funciona como uma qualificação qualitativa de revistas científicas em ciências sociais e humanas, que são classificadas em grupos de acordo com as exigências a serem cumpridas (GA, GB, GC, GD e GEX), porém, a mesma integra apenas os produtos de avaliação, como Latindex, que são considerados e fazem parte de agências como a Comissão Nacional de Avaliação de Atividades de Investigação (CNEAI) e Agência Nacional de Avaliação e Creditação de Qualidade (ANECA), ou seja, periódicos pertencentes às bases de dados dessas agências estão incluídos automaticamente na classificação CIRC, salvo os periódicos incluídos há pouco tempo, que não estão qualificados ainda nas bases de dados. A CIRC foi criada para gerar uma espécie de ferramenta que fosse capaz de facilitar a construção de indicadores bibliométricos para os pesquisadores e demais estudiosos na área da bibliometria.

Em resumo, tomando como premissa as principais bases de dados em nível internacional, os critérios de qualidade fundamentais que são levados em consideração para avaliação de um periódico são: as características básicas do periódico; os aspectos referentes à apresentação formal do mesmo; a tipologia de conteúdo e autoria; os aspectos de gestão e política editorial do periódico (S. Ferreira, 2005, p. 272).

Compreendendo a importância da base de dados Latindex, que dá maior visibilidade às revistas científicas dos países periféricos aí editadas, no compartilhamento de informação e até mesmo na geração de novos conhecimentos, emerge o seguinte questionamento: De que forma os periódicos dos países ibero-americanos que abordam sobre tecnologias educativas obedecem aos critérios de qualidade estabelecidos no catálogo 2.0 pela Latindex? A avaliação dos periódicos se deu a partir do catálogo 2.0, pois este lista as revistas selecionadas por meio de critérios de avaliação de qualidade, dentre os quais se destaca a revisão por pares. Com relação à escolha da área tecnologias educativas, esta se deu por uma das autoras deste artigo ser membro do Grupo de Estudo e Pesquisa em Tecnologias Digitais na Educação.

Diante do exposto, a pesquisa tem como objetivo geral analisar as observâncias, em maior ou menor grau, aos critérios estabelecidos no catálogo 2.0 pela Latindex e como específicos: elencar os periódicos que abordam sobre tecnologias educativas indexados no catálogo 2.0 e pontuar os periódicos que preencheram o maior número de critérios.

O texto está organizado da seguinte forma: de início serão abordados, a partir de revisão de literatura, os temas relacionados ao periódico científico e bases de dados; apresentação da base de dados Latindex; análise do catálogo 2.0, assim como dos periódicos que abordam sobre tecnologias educativas e que cumprem os critérios por ele estabelecido. O texto se encerra com algumas conclusões e considerações que refletem sobre a importância da avaliação das publicações, no caso dos periódicos científicos, como critério de certificação das pesquisas e consequente desenvolvimento da ciência.

\section{MÉTODO E PROCEDIMENTOS}

\section{O contexto de investigação: Base de dados Latindex}

Uma das maneiras de se aferir qualidade à produção científica é mediante a avaliação dos periódicos de forma quantitativa e qualitativa, pelas bases de dados nas quais os mesmos se encontram indexados, de acordo com os critérios que elas estabelecem, ou seja, as bases de dados são sistemas de informação responsáveis pela coleta de dados sobre revistas selecionadas a partir de um conjunto de critérios. 
Os primeiros serviços de indexação surgiram como iniciativas particulares de indivíduos preocupados com o controle e o acesso à informação científica logo após a invenção da imprensa. Porém, os indexadores com abrangência internacional tiveram início nos anos de 1950 com a criação do Web of Science (WOS) pelo Institute os Scientific Information (ISI). O ponto negativo dessas bases com nível internacional se dá justamente pelo fato de elas excluírem da sua gama de avaliação os periódicos e publicações que estejam fora do seu eixo geográfico ou que provenham de fora dos centros consagrados cientificamente.

Em consonância, surgiram, no começo dos anos 1990, outras bases de dados no eixo Ibero-americano na tentativa de corrigir tal discrepância. É o caso do Latindex, sistema de informação criado em 1995 no México. Essas bases de dados vieram com o objetivo de diminuir as fronteiras que limitavam tanto o acesso aos periódicos quanto às pesquisas científicas produzidas nessas regiões.

A Latindex é um Sistema Regional de Informação para periódicos eletrônicos da América Latina, América Central, América do Sul, Caribe, Espanha e Portugal que existe desde 1995. Criada pela Universidade Nacional Autônoma do México (UNAM), desde 1997, a base de dados é alimentada de forma compartilhada por uma rede de instituições para difundir os periódicos que são editados nesses países, que tem como objetivo primordial melhorar a qualidade dos periódicos produzidos nos mesmos (Latindex, 2019).

Seus objetivos particulares são:

a) Integrar os esforços realizados na região em termos de produção, divulgação, registro e uso de periódicos acadêmicos;

b) Reforçar e elevar a qualidade e o impacto de nossos periódicos;

c) Proporcionar aos periódicos ibero-americanos maior visibilidade e cobertura internacional;

d) Usar as informações processadas para a produção de subprodutos;

e) Influenciar os níveis nacionais e internacionais em termos de informação, documentação e publicação científica (Latindex, 2019).

A base de dados Latindex possui dois serviços principais de informação bibliográfica: o diretório, que fornece apenas informação bibliográfica e contato de todos os periódicos cadastrados na base; e o catálogo 2.0, que é composto pelos periódicos com os mais elevados padrões de qualidade, de acordo com os critérios estabelecidos pela própria Latindex.

\begin{tabular}{|c|c|c|c|c|}
\hline $\begin{array}{l}\text { Características bá- } \\
\text { sicas }\end{array}$ & $\begin{array}{l}\text { Características de } \\
\text { apresentação }\end{array}$ & $\begin{array}{l}\text { Características de } \\
\text { gestão e política } \\
\text { editorial }\end{array}$ & $\begin{array}{l}\text { Características de } \\
\text { conteúdo }\end{array}$ & $\begin{array}{l}\text { Características de } \\
\text { revistas On-line }\end{array}$ \\
\hline $\begin{array}{l}\text { 1.Gerentes editori- } \\
\text { ais }\end{array}$ & $\begin{array}{l}\text { 8.Navegação e } \\
\text { funcionalidade no } \\
\text { acesso ao conteúdo }\end{array}$ & $\begin{array}{l}\text { 15.Definição da re- } \\
\text { vista }\end{array}$ & $\begin{array}{l}\text { 23.Conteúdo origi- } \\
\text { nal }\end{array}$ & $\begin{array}{l}31 . \text { Uso de protoco } \\
\text { los de interoperabi- } \\
\text { lidade }\end{array}$ \\
\hline $\begin{array}{l}\text { 2.Geração Contínua } \\
\text { de Conteúdo }\end{array}$ & $\begin{array}{l}\text { 9.Acesso histórico } \\
\text { ao conteúdo }\end{array}$ & $\begin{array}{l}\text { 16.Autores exter- } \\
\text { nos }\end{array}$ & $\begin{array}{l}\text { 24.Elaboração de } \\
\text { referências }\end{array}$ & $\begin{array}{l}\text { 32.Uso de diferen- } \\
\text { tes formatos de edi- } \\
\text { cão }\end{array}$ \\
\hline $\begin{array}{l}\text { 3.Identificação dos } \\
\text { autores }\end{array}$ & $\begin{array}{l}\text { 10.Menção de peri- } \\
\text { odicidade }\end{array}$ & $\begin{array}{l}\text { 17.Abertura Edito- } \\
\text { rial }\end{array}$ & $\begin{array}{l}\text { 25. Requisito de ori- } \\
\text { ginalidade }\end{array}$ & $\begin{array}{l}\text { 33.Serviços de valor } \\
\text { agregado }\end{array}$ \\
\hline $\begin{array}{l}\text { 4.Entidade editorial } \\
\text { da revista }\end{array}$ & $\begin{array}{l}\text { 11.Papel timbrado } \\
\text { bibliográfico no iní- } \\
\text { cio do artigo }\end{array}$ & $\begin{array}{l}\text { 18.Serviços de in- } \\
\text { formação }\end{array}$ & 26.Resumo & $\begin{array}{l}34 . \text { Serviços de inte- } \\
\text { ratividade com o lei- } \\
\text { tor }\end{array}$ \\
\hline $\begin{array}{l}\text { 5.Instruções aos au- } \\
\text { tores }\end{array}$ & $\begin{array}{l}\text { 12.Afiliação institu- } \\
\text { cional dos membros } \\
\text { dos órgãos editori- } \\
\text { ais }\end{array}$ & $\begin{array}{l}\text { 19.Conformidade } \\
\text { periódica }\end{array}$ & $\begin{array}{l}\text { 27.Resumo em duas } \\
\text { línguas }\end{array}$ & $\begin{array}{l}\text { 35.Mecanismos de } \\
\text { pesquisa }\end{array}$ \\
\hline $\begin{array}{l}\text { 6.Sistema de Arbi- } \\
\text { tragem }\end{array}$ & $\begin{array}{l}\text { 13.Afiliação dos au- } \\
\text { tores }\end{array}$ & $\begin{array}{l}\text { 20.Políticas de } \\
\text { acesso e reutiliza- } \\
\text { ção }\end{array}$ & 28.Palavras-chave & $\begin{array}{l}\text { 36. Uso de identifi- } \\
\text { cadores uniformes } \\
\text { de recursos }\end{array}$ \\
\hline \multirow[t]{2}{*}{ 7.ISSN } & $\begin{array}{l}\text { 14.Datas de recep- } \\
\text { ção e aceitação de } \\
\text { originais }\end{array}$ & $\begin{array}{l}\text { 21.Adoção de códi- } \\
\text { gos de ética }\end{array}$ & $\begin{array}{l}\text { 29.Palavras-chave } \\
\text { em duas línguas }\end{array}$ & $\begin{array}{l}\text { 37.Uso de estatísti- } \\
\text { cas }\end{array}$ \\
\hline & & $\begin{array}{l}\text { 22.Detecção de plá- } \\
\text { gio }\end{array}$ & $\begin{array}{l}\text { 30.Número de arti- } \\
\text { gos publicados por } \\
\text { ano }\end{array}$ & $\begin{array}{l}\text { 38.Políticas de pre- } \\
\text { servação digital }\end{array}$ \\
\hline
\end{tabular}

Quadro 1. Critérios de qualidade Catálogo 2.0 da Latindex Fonte: Recuperado de Latindex (2019). 
Para o periódico ser qualificado no catálogo 2.0 da Latindex, ele precisa possuir algumas características específicas, como: ter, no mínimo, dois anos, que devem ser comprovados no site de cada periódico; o site do periódico deve permitir acesso livre a todo o conteúdo, ou seja, a nova lista de critérios do catálogo 2.0, não pode ser aplicada aos periódicos com acesso restrito, salvo os periódicos que permitirem o acesso apenas para a qualificação da Latindex; cada característica que se fizer cumprida equivale a um ponto, entre outras (Latindex, 2019). As características a serem cumpridas pelos periódicos para entrar no catálogo 2.0, serão apresentadas no (Quadro 1).

Ademais, para entrar no Catálogo 2.0, os periódicos devem cumprir as sete características básicas obrigatórias e no mínimo 23 das demais características para que possam obter uma pontuação mínima de 30 pontos, em que o periódico no fim possa totalizar $80 \%$ dos critérios estabelecidos.

Os países em questão, entre os de língua espanhola, detêm o maior número de periódicos indexados e qualificados na Latindex. No catálogo 2.0 encontram-se indexados 21 periódicos. No portal, a soma dos produtos (diretório, catálogo 2.0 e revistas online), dentro da categoria estabelecida para a pesquisa: tecnologias educativas, os países em questão possuem um total de 132 periódicos indexados assim distribuídos: Peru: 7 periódicos eletrônicos; México: 71 periódicos eletrônicos; Espanha: 44 periódicos; Venezuela: 10 periódicos, sendo que $95 \%$ do total dos periódicos desses países, todos no idioma espanhol, é de acesso restrito.

A pesquisa caracteriza-se como descritiva, pois objetiva apontar as características dos periódicos eletrônicos ibero-americanos que abordam a temática tecnologias educativas qualificados no catálogo 2.0 indexados na base de dados Latindex. Para a escolha da amostra da pesquisa, teve-se como universo 21 periódicos ibero-americanos que abordavam o tema tecnologias educativas dentro da área ciências sociais, porém optou-se por considerar apenas os periódicos que tivessem acesso livre, dado a importância que a própria base de dados atribui quando elenca na sua metodologia que só serão qualificados os periódicos de acesso livre.

Assim, foram descartados 15 periódicos que pertencem à categoria selecionada, porém não são de acesso livre. Logo, a amostra final se deu pela escolha de 6 periódicos, que foram recuperados da seguinte forma na busca avançada na base de dados: 1. Tema: Ciências Sociais; 2. Subtema: Tecnologias educativas; 3. Região: Iberoamérica; 4. Situação: Vigente; 5. Suporte: online; 6. Acesso livre: Sim.

Os periódicos analisados pertencem aos seguintes Países:

a) Peru: Periódico Hamut'ay;

b) México: Periódico Estudios de cultura maya e Travaux et recherches dans les Amériques du Centre - Trace;

c) Espanha: Periódicos AP: Online Journal in Public Archaeology e Revista electrónica de investigación y docencia;

d) Venezuela: Revista Scientific.

Dado importante a ser levado em consideração diz respeito ao fato de os periódicos aqui estudados estarem indexados em diversas bases de dados internacionais - cinco dos seis periódicos disponibilizam essas informações em seus sites. Os periódicos do México, Estudios de cultura maya e Travaux et recherches dans les Amériques du Centre - Trace, por exemplo, estão indexados em bases de dados como: DOAJ, DIALNET, Science direct, Scielo, Google acadêmico, Scopus, Redib, Biblat e Redial. O periódico Scientific da Venezuela se encontra indexado em bases de dados como: Seriunam, Sherpa/Romeo, Road, Redib, DOAJ e Clase. O Hamut'ay do Peru se encontra indexado nas seguintes bases: Redib, DIALNET, Alicia, Road e Actualid Iberoamericana. Já o periódico da Espanha, o AP: Online Journal in Public Archaeology, não disponibilizou essa informação e também não houve resultado buscando o ISSN do periódico nas principais bases de dados internacionais, e a Revista electrónica de investigación y docencia, está indexado nas bases de dados a seguir: Resh, Dulcinea, DIALNET e Capes - Web Qualis.

Os principais aspectos que devem ser considerados quando se trata de avaliação de periódicos de uma determinada base de dados, são os critérios elencados pela própria base. A Latindex, como já visto anteriormente, possui 38 critérios de avaliação, que englobam as seguintes características: básicas, de apresentação do periódico; de gestão e política editorial; de conteúdo; e de uma revista on-line.

Desse modo, para análise dos critérios de qualidade dos periódicos eletrônicos ibero-americanos indexados e qualificados no catálogo 2.0 da Latindex, a pontuação se dará da mesma forma que funciona a metodologia da Latindex, ou seja, cada critério vale 1 ponto, sendo que todas as sete características básicas são obrigatórias.

\section{ANÁLISE DOS CRITÉRIOS DE QUALIDADE DOS PERIÓDICOS ELETRÔNICOS IBERO-AMERICANOS EM ACESSO ABERTO NA ÁREA DE TECNOLOGIAS EDUCATIVAS QUALIFICADOS NO CA- TÁLOGO 2.0 DA BASE DE DADOS LATINDEX}

Todos os periódicos conseguiram 7 pontos nos critérios referentes às características básicas do catálogo 2.0 da Latindex. As características básicas, como já mencionadas, se referem aos gerentes editoriais (1), que são os 
editores responsáveis pelos periódicos - são o corpo editorial completo (editores, equipe técnica e autoridades) do mesmo. A importância nesse quesito se dá justamente pelo fato de os periódicos disponibilizarem, em seus sites, todas as informações referentes ao corpo editorial, como nomes e funções desempenhadas; à geração contínua de conteúdo (2), que diz respeito à periodicidade, que deve obedecer a uma agenda ininterrupta.

A periodicidade regular é fundamental para a solidificação e permanência do periódico. Ela varia em cada área, mas em geral [...] a exigência é de periodicidade semestral no mínimo, considerando a necessidade de que as datas previstas para lançamento sejam cumpridas (Gruszynski e Sanseverino, 2005, p. 7).

Ainda referente às características básicas, todos os periódicos cumpriram os critérios ao apresentar em suas páginas on-line todas as instruções aos autores (5), que "[...] devem ser claras e abrangentes para facilitar a normalização dos artigos, orientar os autores e dar autoridade ao periódico para devolver trabalhos que não estejam dentro dos parâmetros da revista" (M. C. G. Ferreira e Krzyzanowski, 2003, p. 46-47). Todos periódicos possuem revisão por pares, ou seja, sistema de arbitragem (6), mesmo diante de diversas críticas da comunidade científica, que são "[...] motivadas pelas distorções do seu uso", tanto os periódicos quanto as bases indexadoras compreendem que o sistema de arbitragem ajuda a melhorar a comunicação cientifica, além de melhorar a qualidade das publicações (Pessanha, 1998, p. 226). A última característica básica analisada e cumprida por todos os periódicos trata-se da característica de número 7 que consiste em ter registro no International Standard Serial Number (ISSN), e apresentá-lo sem erros no site do periódico, o que viabiliza e contribui posteriormente para recuperação do periódico nas bases de dados.

Quanto às características de apresentação, todos os periódicos voltaram a conseguir pontuação 7 nessa categoria. Os periódicos analisados cumpriram os seguintes critérios: navegação e funcionalidade no acesso ao conteúdo (8), acesso histórico ao conteúdo (9), menção de periodicidade (10), papel timbrado bibliográfico no início do artigo (11), afiliação institucional dos membros dos órgãos editoriais (12), afiliação dos autores (13) e data de recepção e aceitação dos originais (13).

Em referência ao critério navegação e funcionalidade no acesso ao conteúdo (8), o site do periódico deve ter resumos, tabelas de conteúdo, além de uma estrutura que permita o acesso a artigos em no máximo três cliques, que visa justamente facilitar o acesso ao autor/leitor do mesmo. Quanto ao quesito acesso histórico ao conteúdo (9), que todos os periódicos cumpriram, diz respeito a ter as informações e publicações publicados até cinco anos antes do ano vigente. Outra característica de apresentação elencada e cumprida pelos periódicos foi referente à menção de periodicidade (10), que deve estar visível e disponível no site dos mesmos, além dos números de fascículos, se houver, e se o periódico é de periodicidade contínua ou não. Afiliação de membros institucionais (12) e afiliação dos autores (13), são outras características que se fizeram cumpridas pelos periódicos, a precisão na apresentação das informações, sem erros, como: nome completo da instituição de trabalho do autor, nomes completos das instituições às quais pertencem os membros dos diferentes órgãos editoriais, visam melhorar o processo e apresentação editorial do periódico.

As demais características de apresentação que foram cumpridas pelos periódicos analisados, são: papel timbrado bibliográfico no início do artigo (11) e datas de recebimento e aceitação dos originais (14). O primeiro consiste em incluir o cabeçalho bibliográfico no início de cada artigo e o segundo, em incluir as datas de recebimento e aceitação dos originais. Ressalta-se que o catálogo exige que sejam apresentadas as duas datas (Latindex, 2019).

Das oito características pertencentes ao grupo de gestão e política editorial, cinco foram cumpridas por todos os periódicos analisados. A característica serviços de informação (18) não foi cumprida pelo periódico AP: Online Journal in Public Archaeology, característica que diz respeito a disponibilizar as demais bases de dados em que estão indexadas. Não foi cumprida também a característica adoção de códigos de ética (21), pelo Travaux et recherches dans les Amériques du Centre - Trace. Os periódicos AP: Online Journal in Public Archaeology, Estudios de cultura maya, Revista electrónica de investigación y docencia e Travaux et recherches dans les Amériques du Centre - Trace não obedeceram ao critério detecção de plágio (22). É possível notar, a partir desta categoria e da categoria relacionada às características de conteúdo, que alguns dos periódicos analisados se preocupam em demasia em captar originais, porém, recusam-se a indicar quais são seus critérios e políticas para detecção de plágio.

Ainda no bloco das características de gestão e política editorial, os periódicos conseguiram pontuar nos critérios referentes a: definição da revista (15), autores externos (16), abertura editorial (17), conformidade periódica (19) e políticas de acesso e reutilização (20). Sobre a definição da revista, a Latindex pede que todos os periódicos, para constarem no catálogo 2.0, apresentem em seu site o seu objetivo, sua área temática e seu público-alvo.

Quanto à abertura editorial (17), a Latindex elenca que pelo menos dois terços dos membros do corpo editorial e de publicação devem pertencer a instituições que não sejam a entidade editorial, pois "[...] a qualidade do conteúdo de um periódico é que vai determinar o seu mérito", portanto, a qualidade do corpo editorial, mediante a participação de membros da comunidade nacional e internacional se faz imprescindível (M. C. G. Ferreira \& Krzyzanowski, 2003, p. 45). 
Em referência a autores externos (16), os periódicos analisados cumpriram o quesito sobre ter pelo menos $50 \%$ de trabalhos vindos de autores de outras instituições externas à entidade editorial. Cabe esclarecer que esta investigação é da própria base Latindex: "Para contar a porcentagem, ela será revisada nos artigos de pesquisa originais, em artigos de revisão, artigos de opinião, ensaios e casos clínicos, se houver pelo menos uma 'autoria externa' na instituição editora da revista." (Latindex, 2019). Tal característica é necessária e contribui exponencialmente para a qualidade de um periódico, a "[...] abrangência quanto à origem dos trabalhos, visa permitir uma abertura, por parte do periódico para autores de nível institucional, nacional e internacional, garantindo assim maior disseminação e alcance das pesquisas, além do órgão editorial ao qual o periódico pertence." (M. C. G. Ferreira e Krzyzanowski, 2003, p. 45).

Todos os periódicos cumpriram a característica correspondente às políticas de acesso e reutilização (20). Essa característica se refere às informações sobre quais as políticas de direitos autorais em relação ao acesso de seus arquivos. Em tese é o modo como o periódico permite que reutilizem as informações nele contidas e deve ser especificado, como exemplo, uso de licenças Creative Commons (Latindex, 2019). As licenças Creative Commons, "[...] tem por base a ideia de flexibilização, possibilitando a propagação das obras participativas, a melhor divulgação das criações e uma maior liberdade na utilização dos conteúdos [...]" (Consalter e Chaves, 2011, p. 179). Nesse sentido, pode-se afirmar que o creative commons funciona como um instrumento que visa acabar com as barreiras que impedem o acesso livre às publicações científicas.

No que tange às características de conteúdo, estas são compostas pelos seguintes critérios: conteúdo original (23), elaboração de referências bibliográficas (24), requisito de originalidade (25), resumo (26), resumo em duas línguas (27), palavras-chave (28), palavras-chave em duas línguas (29) e número de artigos publicados por ano (30). Os periódicos Estudios de cultura maya e Travaux et recherches dans les Amériques du Centre - Trace não cumpriram o critério elaboração de referências bibliográficas (24), que corresponde a "[...] instruções aos autores devem indicar as normas de elaboração das referências bibliográficas adotando um padrão internacional amplamente aceito (APA, Harvard, ISO, Vancouver ou algum outro)" (Latindex, 2019). Vale ressaltar que, se o periódico possuir um padrão considerado próprio em vez de seguir os padrões internacionais de normalização e elaboração de referências bibliográficas, esse critério, de acordo com a metodologia da Latindex, será considerado descumprido e não pontuará nesse quesito. O que é compreensível, visto que "É importantíssimo uniformizar a apresentação das referências, pois isso facilitará a identificação dos trabalhos referenciados, agilizando a sua localização e obtenção" (M. C. G. Ferreira e Krzyzanowski, 2003, p. 46).

Dando continuidade às caraterísticas de conteúdo, os critérios 27 e 29, que correspondem, respectivamente, a resumo em duas línguas e palavras-chave em duas línguas, não foram cumpridos pelo periódico espanhol $A P$ : Online Journal in Public Archaeology. Entendendo a importância e mudança que uma pesquisa pode causar na comunidade científica, é necessário e quase inviável que um trabalho publicado, fruto de pesquisas científicas, possua resumo e palavras-chave apenas em sua língua materna. A comunidade científica e não somente ela, mas o mundo globalizado, demandam que periódicos indexados em base de dados internacionais, principalmente, divulguem seus resumos em mais de uma língua para que a disseminação da pesquisa ocorra de fato sem restrições em termos linguísticos.

Os demais critérios pertencentes às características de conteúdo, como: conteúdo original (23), requisito de originalidade (25), resumo (26), palavras-chave (28) e números de artigos publicados por ano (30), foram cumpridos por todos os periódicos pesquisados. Em observância aos critérios de originalidade (23) e (25), pode-se afirmar que estes se cruzam, pois o requisito de originalidade corresponde às instruções sobre originalidade dos trabalhos que devem estar explícitas aos autores no site, e o conteúdo original, que a Latindex elenca que pelo menos $40 \%$ dos trabalhos publicados nos periódicos sejam originais (Latindex, 2019). Sobre os resumos (26), sua relevância em se fazer presente junto ao trabalho publicado está justamente por ser o primeiro contato do leitor com a pesquisa após o título. Portanto, deve ser conciso e transmitir informações complementares:

\footnotetext{
Apresentação concisa dos pontos relevantes de um texto (até 250 palavras). Os resumos permitem ao leitor decidir sobre a necessidade de consulta ao texto original e/ou transmitir informações de caráter complementar. Facilitam também o trabalho dos indexadores de bases de dados (M. C. G. Ferreira e Krzyzanowski, 2003, p. 46).
}

Quanto ao critério palavras-chave (28), que também foi cumprido por todos os periódicos analisados, a Latindex elenca sua importância colocando como regra que "[...] todos os artigos originais, resenhas e ensaios serão revisados e, se uma ou mais palavras-chave estiverem faltando, o critério será perdido" (Latindex, 2019). As palavras-chave funcionam como:

[...] termos indicativos do conteúdo dos artigos e devem ser escolhidos, sempre que possível, utilizando-se vocabulários controlados. São muito importantes para a indexação correta dos artigos em bases de dados e para a futura busca dos artigos por assunto (M. C. G. Ferreira e Krzyzanowski, 2003, p. 46).

Em prosseguimento à análise, as características de revista on-line são os últimos critérios a serem analisados, compostos por: uso de protocolo de interoperabilidade (31), uso de diferentes formatos de edição (32), serviços 
de valor agregado (33), serviço de interatividade com o leitor (34), mecanismos de pesquisa (35), uso de identificadores uniformes de recursos (36), uso de estatísticas (37), e políticas de preservação digital (38). Os únicos critérios dessa categoria cumpridos por todos os periódicos foram: o serviço de valor agregado (33), que se refere a incluir serviços adicionais como RSS, multimídia (vídeo), ter presença em redes sociais de abrangência acadêmica, além de instruções sobre como citar os artigos, entre outros; e o uso de identificadores uniformes de recursos (36), que corresponde a recursos como Identificador Digital ou Identificador de Objeto Digital (DOI). (Latindex, 2019). A importância da adoção do (DOI) por parte do periódico, se equivale porque o mesmo é:

[...] um sistema que permite a identificação, localização e descrição unívoca de entidades digitais físicas ou abstratas. Atualmente, tem sido muito adotado na Internet, devido, principalmente, às necessidades de padronização e preservação das informações contidas nesse ambiente (Brito, Shintaku, Soares, e Weber, 2016, p. 8).

Ou seja, o DOI permite acesso ao texto integral, apenas tendo em mãos o identificador. Sobre o uso de protocolos de interoperabilidade (31), três periódicos não pontuaram nesse critério: AP: Online Journal in Public Archaeology, Revista Scientific e Travaux et recherches dans les Amériques du Centre - Trace. O uso de protocolos de interoperabilidade, permite que, em tese, as informações e publicações sejam trocadas com outras bases de dados e/ou sistemas de distribuição. O fato de o site dos periódicos não disponibilizar a informação, não significa necessariamente que eles não façam uso do protocolo.

O critério 32, correspondente ao uso de diferentes formatos de edição, não foi cumprido também por três periódicos: AP: Online Journal in Public Archaeology, Revista electrónica de investigación y docencia e Travaux et recherches dans les Amériques du Centre - Trace. O uso de diferentes tipos de formatos de edição, de acordo com a Latindex, procura expandir o uso do PDF, o uso de HTML e outros formatos que facilitam o hipertexto e a leitura.

O critério serviço de interatividade com o leitor (34) não foi cumprido pelos seguintes periódicos: AP: Online Journal in Public Archaeology, Revista Electrónica de Investigación y Docencia, Revista Scientific e Travaux et recherches dans les Amériques du Centre - Trace. Esse serviço é um espaço em que o leitor poderia participar, deixando comentários, participando de pesquisas ou de revisão de artigos ou publicações, como blogs, espaços para comentários, fóruns de discussão, entre outros (Latindex, 2019).

Sobre o critério 35, apenas o periódico Travaux et recherches dans les Amériques du Centre - Trace não pontuou. O critério, de acordo com a metodologia da Latindex, verifica se o mecanismo de pesquisa da página do periódico funciona, ou seja, se seu mecanismo permite buscas por palavras ou índices, bem como utilizar formas de buscas boolena etc. Os critérios uso de estatísticas (37) e políticas de preservação digital (38) são recentes, foram implantados à metodologia e ao catálogo 2.0. Até o último catálogo da Latindex, os critérios de avaliação iam só até o critério uso de identificadores uniformes de recursos (36).

As novas adições visam melhorar ainda mais a qualidade da qualificação dada aos periódicos, ao analisarem critérios como uso de estatísticas (37), que contribui para fornecer dados estatísticos sobre a própria página do periódico, tais como visita/acessos, citações etc. e políticas de preservação digital (38), em que o periódico deve informar as políticas que rege e/ou implementou. Porém, para pontuar nesse critério, "[...] não basta que a revista imprima o logotipo do LOCKSS ou mostre o texto padrão usado pelo gerente do OJS, ele deve detalhar suas políticas de preservação" (Latindex, 2019).

O único periódico que pontuou em todos esses critérios conseguindo pontuação máxima, no catálogo 2.0 da Latindex, foi o peruano Hamut'ay como pode ser visto na Tabela 1.

\begin{tabular}{|l|c|c|}
\hline Periódicos & $\begin{array}{c}\text { Número de critérios não } \\
\text { pontuados }\end{array}$ & $\begin{array}{c}\text { Forma de obediência } \\
\text { aos critérios (Pontos) }\end{array}$ \\
\hline Hamut'ay & - & Total 38 pontos \\
\hline Revista Scientific & 31,34 & Parcial 36 pontos \\
\hline Estudios de cultura maya & $22,24,38$ & Parcial 35 pontos \\
\hline Revista electrónica de investigación y docencia & $22,32,34,37,38$ & Parcial 33 pontos \\
\hline AP: Online Journal in Public Archaeology & $18,22,27,29,31,32,34,37$ & Parcial 30 pontos \\
\hline Travaux et recherches dans les Amériques du Centre (Trace) & $21,22,24,31,32,34,35,37$ & Parcial 30 pontos \\
\hline
\end{tabular}

Tabela 1. Pontuação dos periódicos de acordo com os critérios estabelecidos no catálogo 2.0 pela Latindex

\section{CONSIDERAÇÕES FINAIS}

Este estudo se propôs a analisar os critérios de qualidade dos periódicos ibero-americanos na área de tecnologias educativas indexados na base de dados Latindex. Após a pesquisa, verificou-se que o Hamut'ay se destacou como o único periódico a pontuar em todos os critérios estabelecidos pelo catálogo 2.0 da Latindex. 
Observou-se que todos os periódicos cumpriram acima dos 23 pontos (pontuação mínima) para serem qualificados pelo catálogo. Os periódicos que menos pontuaram, 30 pontos cada uma, foram o espanhol AP: Online Journal in Public Archaeology e o mexicano Travaux et recherches dans les Amériques du Centre - Trace, este deixou de pontuar em critérios de uma característica em específico, apenas três pontos nas características de revista on-line $(33,36,38)$. A possível resposta para tal desempenho talvez seja pelo fato de dois desses critérios serem recém-adicionados e, por isso, os periódicos ainda não estarem de acordo com a demanda da base de dados.

Percebeu-se também que quatro dos periódicos analisados - AP: Online Journal in Public Archaeology, Estudios de cultura maya, Revista electrónica de investigación y docencia e Travaux et recherches dans les Amériques $d u$ Centre - Trace - não disponibilizam no seu site informações sobre detecção de plágio, mesmo a Latindex deixando claro na metodologia do catálogo 2.0 que o periódico deve manifestar as políticas de detecção de plágio. Mesmo assim, os periódicos omitem a informação, abrindo, portanto, precedente para dúvidas quanto a qualidade dos originais das publicações.

Outro critério importante e que contribui para aumentar a qualidade do periódico e de suas publicações é o fato de todos os periódicos analisados possuírem editores externos em seu corpo editorial e autores externos em suas publicações.

Por fim, ressalta-se a importância que a própria base de dados Latindex dá ao conteúdo em acesso livre, pois desde os critérios para qualificação dos periódicos, tal aspecto fica explícito. Os periódicos, por sua vez, mesmo não sendo parte dos critérios obrigatórios, fazem uso da licença creative commons, que flexibiliza e permite a propagação das pesquisas e publicações, contribuindo assim para a disseminação e divulgação da ciência. 


\section{REFERÊNCIAS}

Barbalho, C. R. S. (2005). Periódicos científicos em formato eletrônico: elementos para sua avaliação. In Congresso brasileiro de ciências da comunicação (v. 28). Rio de Janeiro, RJ, Brasil. Recuperado de http://www.portcom.intercom.org .br/pdfs/144299010318091916156725937486754826190.pdf

Brito, R. F., Shintaku, M., Soares, S. d. B. C., \& Weber, C. (2016). Guia do usuário do digital object identifier. Brasília: IBICT. Recuperado de https://www.abecbrasil .org.br/arquivos/Guia_usuario_DOI-online3.pdf

Castro, C. F., R. (2003, Setembro). Como uma revista científica pode ser indexada em bases de dados e fontes de indexação? Curso de Editoração Científica da ABEC, 11.

Consalter, Z. M., \& Chaves, B. R. G. (2011). Creative commons: a importância de flexibilizar as regras sobre os direitos autorais para que estes possam perdurar. Revista do Curso de Direito da FGS Caxias do Sul ano, 5(10), 165-180.

Corrêa, T. P. P., \& Miranda, A. C. D. (2016). Critérios de qualidade em revistas científicas de acesso aberto em educação da região sul do brasil. Revista Brasileira de Educação em Ciência da Informação, 3(2), 51-66. Recuperado de https://portal.abecin.org.br/rebecin/article/view/48/pdf

Ferreira, M. C. G., \& Krzyzanowski, R. F. (2003). Periódicos científicos: critérios de qualidade. Pesquisa Odontológica Brasileira, 17(1), 43-48.

Ferreira, S. (2005). Critérios de qualidade para as revistas científicas em comunicação. Preparação de revistas cientificas: teoria e prática. São Paulo: Reichmann \& Autores, 269-293.

Fukahori, M. A. V. (2017). As práticas de publicação científica das áreas de ciência da informação, comunicação, letras e artes: as preferências dos bolsistas de produtividade em pesquisa pq1 e pq-sr do cnpq (Dissertação de mestrado). Programa de Pós-Graduação em Ciência da Informação, Universidade Federal de Pernambuco, Recife, PE, Brasil.

Gruszynski, A. C., \& Sanseverino, A. M. (2005). O periódico científico na área de humanidades: critérios de avaliação. In Congresso brasileiro de ciências da comunicação (v. 28). Rio de Janeiro, RJ, Brasil. Recuperado de http://www.portcom.intercom.org.br/pdfs/ 47533372324880452232867111468010739789.pdf

Krzyzanowski, R. F., \& Ferreira, M. C. G. (1998). Avaliação de periódicos científicos e técnicos brasileiros. Ciência da informação, 27(2), 165-175. Recuperado de https://www.scielo.br/scielo.php?pid=S0100 $-19651998000200009 \&$ script $=$ sci_abstract\&tlng $=$ pt

Latindex. (2019). Sistema regional de información en línea para revistas científicas de américa latina, el caribe, españa y portugal. Recuperado de https://latindex.org/latindex/ inicio

Meadows, A. J. (1999). A comunicação científica. Brasília: Brinquet de Lemos Livros.

Mueller, S. P. M. (2012). Literatura científica, comunicação científica e ciência da informação. Para entender a ciência da informação. Salvador: UFBA.

Passos, P. C. S. J., Passos, J. E., Caregnato, S. E., \& Silva, T. L. K. d. (2018). Critérios de qualidade em periódicos científicos. Informação \& Sociedade: estudos, 28(2), 209226.

Paz-Enrique, L. E. (2018). Actividad editorial y socialización de la ciencia. Santa Clara: Editorial Feijóo.
Pessanha, C. (1998). Critérios editoriais de avaliação científica: notas para discussão. Ciência da Informação, 27(2), 226-229.

Stumpf, I. R. C. (1996). Passado e futuro das revistas científicas. Ciência da Informação, 25(3), 1-6. Recuperado de http://revista.ibict.br/ciinf/article/view/637
Como citar este artigo (APA):

Pecegueiro, C. M. \& Iraceles, L. (2020). Critérios de qualidade dos periódicos eletrônicos em acesso aberto da região Ibero-Americana na área de tecnologias educativas, indexados na base de dados Latindex. AtoZ: novas práticas em informação e conhecimento, 9(1), 22 - 31. Recuperado de: http://dx.doi.org/10.5380/ atoz.v9i1.70893 